\title{
PENGARUH PROFITABILITAS DAN STRUKTUR MODAL TERHADAP NILAI PERUSAHAAN
}

\section{The Effects of Profitability and Capital Structure on the Value of Firm}

\author{
Nova Adhitya Ananda ${ }^{1}$ \\ Program Studi Manajemen, Fakultas Ekonomi dan Bisnis, Universitas Tehnologi Sumbawa
}

Email: novadhitya88@gmail.com

\begin{abstract}
This research is aimed to determine the effect of profitability and capital structure on firm value. This research is using purposive sampling technique in obtaining samples. The data were analyzed using Partial Least Square (PLS) analysis. The research showed that capital structure has a direct and significant effect on the firm value, while the profitability has not any influence on firm value. Profitability has an indirect effect on the firm value through capital structure.
\end{abstract}

Keywords : Profitability, Capital Structure, Firm Value

\section{ABSTRAK}

Tujuan penelitian ini adalah untuk mengetahui pengaruh dari profitabilitas dan struktur modal terhadap nilai perusahaan. Penelitian ini menggunakan teknik purposive sampling dalam penentuan sampel penelitian. Metode analisis data yang digunakan dalam penelitian ini adalah analisis partial least square (PLS). Hasil penelitian menunjukkan secara langsung struktur modal memiliki pengaruh yang signifikan terhadap nilai perusahaan sedangkan profitabilitas tidak berpengaruh terhadap nilai perusahaan. Profitabilitas berpengaruh secara tidak langsung terhadap nilai perusahaan melalui struktur modal.

Kata Kunci ; Profitabilitas, Struktur Modal, Nilai Perusahaan

\section{Pendahuluan}

Perusahaan didirikan dengan tujuan dan sasaran tertentu. Dan yang menjadi tujuan utama perusahaan adalah kemakmuran pemegang saham yang dicapai melalui peningkatan nilai perusahaan. Dalam jangka panjang tujuan perusahaan adalah mengoptimalkan nilai perusahaan. Semakin tinggi nilai perusahaan maka semakin sejahtera pemiliknya (Fama, 1978)

Nilai perusahaan merupakan persepsi investor terhadap perusahaan, yang sering dikaitkan dengan harga saham. Harga saham tinggi membuat nilai perusahaan juga tinggi. Nilai perusahaan sangat penting karena dengan nilai perusahaan yang tinggi akan diikuti oleh tingginya kemakmuran pemegang saham (Brigham \& Houston, 2013). Kemakmuran pemegang saham dicerminkan oleh harga pasar dari saham yang merupakan cerminan dari keputusan investasi, pendanaan dan manajemen aset.

Beberapa faktor yang dapat mempengaruhi nilai perusahaan diantaranya profitabilitas dan struktur modal (Tanujaya, et al., 2016). Dalam penelitian ini rasio profitabilitas diukur menggunakan return on equity (ROE), ROE dapat menunjukan kemampuan perusahaan dalam menghasilkan laba bersih untuk pengembalian ekuitas pemegang saham. Semakin besar nilai ROE maka kinerja perusahaan akan semakin baik (Prasetyorini, 2013). Peningkatan rasio ROE ini menunjukan bahwa pengelolaan sumber dana pembiayaan operasional yang dilakukan oleh manajemen sudah efektif untuk dapat menghasilkan laba bersih (profitabilitas meningkat). Kinerja manajemen dalam mengelola sumber dana pembiayaan secara efektif untuk menciptakan laba bersih menjadi perhatian investor selain memperhatikan aspek efektivitas manajemen dalam mengelola investasi yang sedang dilaksanakan perusahaan. Peningkatan ROE menunjukan bahwa perusahaan memiliki prospek yang baik, sehingga hal ini ditangkap oleh investor sebagai sinyal positif dari perusahaan. Perusahaan akan mudah mendapatkan modal dari saham karena kepercayaan investor terhadap perusahaan meningkat. Investor akan mencari saham perusahaan, ketika terjadi kenaikan permintaan terhadap saham perusahaan maka secara tidak langsung harga saham perusahaan pun akan naik dipasar modal. 
Penelitian yang dilakukan oleh Ayem dan Nugroho (2016) menunjukan bahwa profitabilitas yang diukur menggunakan Return On Equity (ROE) berpengaruh positif dan signifikan terhadap nilai perusahaan, sedangkan penelitian yang dilakukan oleh Gusaptono (2010) menunjukan bahwa ROE tidak berpengaruh secara signifikan terhadap nilai perusahaan.

Profitabilitas merupakan pendapatan untuk membiayai investasi yang ditujukan untuk menghasilkan keuntungan. Stabilitas profitabilitas merupakan salah satu hal penting yang harus diperhatikan manajer didalam pemilihan struktur modal (Brigham \& Houston, 2013). Perusahaan yang memiliki profit tinggi memungkinkan mereka untuk menggunakan laba ditahan sebagai sumber pendanaan perusahaan dan akan menggunakan hutang dalam jumlah rendah dan sebaliknya. Alasannya, biaya dana internal lebih murah dibanding biaya dana eksternal. Pada variabel profitabilitas, hasil temuan Setyawan, Topowijoyo, Nuzula (2016) menyatakan bahwa profitabilitas berpengaruh signifikan terhadap struktur modal sedangkan hasil temuan Nguyen dan Ramachandran (2006) menyatakan bahwa profitabilitas tidak berpengaruh terhadap struktur modal.

Kebijakan hutang dan struktur kepemilikan modal juga dapat mempengaruhi nilai perusahaan dengan adanya pajak, biaya keagenan, dan biaya kesulitan keuangan sebagai imbangan dari manfaat penggunanaan hutang. Menurut tradeoff teori, hutang bermanfaat bagi perusahaan karena bunga dapat dikurangkan dalam menghitung pajak, tetapi hutang juga menimbulkan biaya yang berhubungan dengan kebangkrutan. Struktur modal yang optimal berada pada keseimbangan antara manfaat pajak atas penggunaan hutang dengan biaya yang berhubungan dengan kebangkrutan, karena biaya dan manfaat akan saling meniadakan satu sama lain. Pada tingkat hutang yang optimal diharapkan nilai perusahaan akan mencapai nilai optimal, dan sebaliknya apabila terjadi tingkat perubahan hutang sampai melewati tingkat optimal atau biaya kebangkrutan, hutang akan mempunyai efek negatif terhadap nilai perusahaan. Penelitian yang dilakukan oleh Moniaga (2013) menemukan bahwa struktur modal yang diproksikan menggunakan debt to equity ratio (DER) berpengaruh signifikan terhadap nilai perusahaan sedangkan Prasetia, Tommy dan Saerang (2014) menemukan bahwa struktur modal tidak berpengaruh signifikan terhadap nilai perusahaan.

Penelitian ini secara eksplisit bertujuan untuk mengetahui pengaruh profitabilitas terhadap struktur modal; kedua, pengaruh profitabilitas terhadap nilai perusahaan, dan pengaruh struktur modal terhadap nilai perusahaan.

\section{Tinjauan Pustaka}

\section{Nilai Perusahaan}

Nilai perusahaan dapat didefinisikan sebagai nilai wajar perusahaan yang menggambarkan persepsi investor terhadap emiten bersangkutan. Menurut Husnan (2001), nilai perusahaan merupakan harga yang bersedia dibayar oleh calon pembeli apabila perusahaan tersebut dijual. Di bursa saham, harga pasar berarti harga yang bersedia dibayar oleh investor untuk setiap lembar saham perusahaan. Oleh karenanya dapat dikatakan bahwa nilai perusahaan adalah merupakan persepsi investor terhadap perusahaan yang selalu dikaitkan dengan harga saham.

\section{Profitabilitas}

Profitabilitas adalah kemampuan perusahaan untuk menghasilkan keuntungan dan mengukur tingkat efisiensi operasional dan efisiensi dalam menggunakan harta yang dimilikinya. Profitabilitas merupakan gambaran dan kinerja manajemen dalam mengelola perusahaan. Pengukuran profitabilitas dapat menggunakan beberapa indikator seperti laba operasi, laba bersih, tingkat pengembalian investasi/aktiva, dan tingkat pengembalian ekuitas pemilik.

\section{Struktur Modal}

Sumber daya keuangan dasar perusahaan adalah aliran kas yang dihasilkan oleh aset/aktiva dan operasinya. Ketika perusahaan didanai seluruhnya oleh saham biasa, semua arus kas itu menjadi milik pemegang saham. Ketika perusahaan menerbitkan utang dan ekuitas sekaligus, perusahaan memecah arus kas menjadi dua aliran, aliran yang relatif aman yang menuju pemegang utang dan aliran yang lebih berisiko yang menuju pemegang saham. Bauran sekuritas perusahaan disebut struktur modalnya (Brealey et al., 2012).

Struktur modal menjadi sangat penting untuk diperhatikan oleh investor karena teori agensi (Horne \& Machowicz, 2010) menjelaskan adanya pertentangan antara manajemen (sebagai agen) dengan pemegang saham. Teori agensi muncul dari konflik-konflik kepentingan diantara manajer dan pemilik saham. Teori tersebut berasal dari pemisahan kepemilikan dan kontrol. Konflik konflik kepentingan yang terjadi di antara manajer dan pemegang saham dikarenakan adanya tujuan yang berlainan (Jensen \& Meckling, 1976).

Asimetri informasi mengemukakan bahwa manajer mempunyai pengetahuan yang lebih luas daripada investor. Hal ini dapat dibuktikan dengan perubahan harga saham akibat suatu keputusan yang diambil manajer. Asymetric information theory merupakan suatu teori yang mengemukakan bahwa manajer perusahaan akan mempunyai informasi yang lebih banyak mengenai prospek dan risiko yang dihadapi 
perusahaan dibandingkan dengan pemegang saham (Myers \& Majluf, 1984).

Penggunaan hutang dapat menjadi sinyal positif terkait potensi pertumbuhan perusahaan di masa depan. Hutang membuat manajer (agen) menjadi tidak sembarangan menggunakan dana yang dimiliki perusahaan untuk kepentingannya sendiri (Williams, 1988).

\section{Profitabilitas Dan Struktur Modal}

Trade off theory menjelaskan perusahaanperusahaan dengan profit yang tinggi cenderung menggunakan lebih banyak pinjaman untuk memperoleh manfaat dalam aspek pajak. Hal ini dikarenakan pengurangan laba oleh bunga pinjaman akan lebih kecil dibandingkan apabila perusahaan menggunakan modal yang tidak dikenai bunga, namun penghasilan kena pajak akan lebih tinggi (Brealey, et al., 2012). Penelitian yang dilakukan oleh Setyawan, Topowijono, dan Nuzula (2016) menunjukan bahwa profitabilitas yang diukur menggunakan return on equity (ROE) berpengaruh positif dan signifikan terhadap struktur modal.

Dengan demikian sesuai dengan teori di atas, maka semakin besar tingkat profitabilitas maka akan semakin besar rasio struktur modal, sehingga profitabilitas berpengaruh positif terhadap struktur modal. Berdasarkan uraian tersebut, hipotesa pertama yang akan diuji adalah profitabilitas berpengaruh positif terhadap struktur modal.

\section{Struktur Modal Dan Nilai Perusahaan}

Hutang bermanfaat bagi perusahaan karena bunga dapat dikurangkan dalam menghitung pajak, tetapi hutang juga menimbulkan biaya yang berhubungan dengan kebangkrutan. Struktur modal yang optimal berada pada keseimbangan antara manfaat pajak atas penggunaan hutang dengan biaya yang berhubungan dengan kebangkrutan, karena biaya dan manfaat akan saling meniadakan satu sama lain. Pada tingkat hutang yang optimal diharapkan nilai perusahaan akan mencapai nilai optimal, dan sebaliknya apabila terjadi tingkat perubahan hutang sampai melewati tingkat optimal atau biaya kebangkrutan, hutang akan mempunyai efek negatif terhadap nilai perusahaan. Disini terdapat trade off antara biaya dan manfaat atas penggunaan hutang. Semakin besar proporsi hutang maka semakin besar perlindungan pajak yang diperoleh, tetapi biaya kebangkrutan yang mungkin timbul juga semakin besar.

Hutang dapat digunakan untuk mengendalikan penggunaan arus kas bebas secara berlebihan oleh manajemen, dengan demikian menghindari investasi yang sia-sia. Ketika manajer memiliki keyakinan kuat atas prospek perusahaan kedepan dan ingin agar harga saham meningkat, maka manajer dapat menggunakan hutang lebih banyak sebagai sinyal yang lebih dapat dipercaya oleh calon investor. Dalam tataran empiris, Safitri dan Wahyuati (2015) menemukan bahwa struktur modal berpengaruh positif terhadap nilai perusahan. Hipotesis kedua yang akan diuji adalah struktur modal berpengaruh positif terhadap nilai perusahaan.

\section{Profitabilitas Dan Nilai Perusahaan}

Profitabilitas dapat dihitung dengan return on equity (ROE). ROE mencerminkan tingkat hasil pengembalian investasi bagi pemegang saham. Profitabilitas yang tinggi mencerminkan kemampuan perusahaan dalam menghasilkan keuntungan bagi pemegang saham. ROE dari segi akuntansi menjadi ukuran hasil akhir kinerja yang sebenarnya (Ross, Westerfield, \& Jordan, 2009). Secara empiris Profitabilitas berpengaruh positif terhadap nilai perusahaan ( Ayem dan Nugroho, 2016 ) artinya bahwa pada saat perusahaan mengalami kenaikan keuntungan maka harga saham perusahaan akan ikut naik dan akan meningkatkan nilai perusahaan. ROE menjadi sebuah tolak ukur bagi para investor tentang kemampuan perusahaan dalam mengelola sumberdaya yang dimiliki dengan efektif atau tidak. Semakin tinggi ROE menunjukan bahwa perusahaan semakin efektif dalam menggunakan modal sendiri dalam menghasilkan laba. Hipotesis ketiga yang akan diuji adalah profitabilitas berpengaruh positif terhadap nilai perusahaan.

\section{Metode Penelitian}

\section{Teknik Estimasi}

Penelitian ini mengaplikasikan pendekatan Partial Least Square (PLS). PLS adalah membantu peneliti untuk mendapatkan nilai variabel laten untuk tujuan prediksi. Variabel laten adalah linear agregat dari indikator-indikatornya. Weight estimate untuk menciptakan komponen skor variabel laten didapat berdasarkan bagaimana inner model (model struktural yang menghubungkan antar variabel laten dan outer model (model pengukuran yaitu hubungan antara indikator dengan konstruknya) dispesifikasi. Hasilnya adalah residual variance dari variabel independen (keduanya variabel laten dan indikator) diminimumkan (Ghozali, 2014)

Langkah-langkah yang dilakukan untuk menganalisis data menggunakan PLS sebagai berikut :

1) Dalam penelitian ini, model struktural yang dianalisis memenuhi model formatif dengan semua indikator dari dua variabel eksogen yaitu Profitabilitas (X1), dan Struktur Modal (X2) dan variabel endogen yaitu Nilai Perusahaan (Y).

2) Diagram jalur (diagram path) PLS, Berdasarkan kerangka konseptual penelitian yang dibangun atas dasar teori dan konsep, 
maka dapat digambarkan model empirik penelitian seperti gambar 1 .

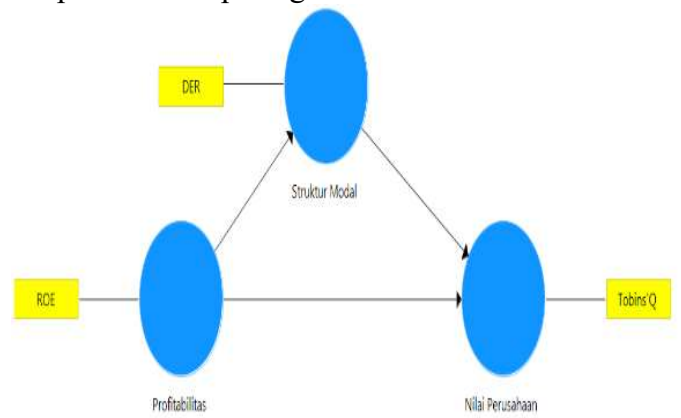

Gambar 1. Diagram jalur PLS

\section{Model Empiris}

Nilai perusahaan diukur dengan Tobins'Q, yang merupakan rasio nilai pasar saham perusahaan terhadap nilai buku ekuitas perusahaan. formulanya adalah :

$$
Q=\frac{E M V+D}{E B V+D}
$$

Dimana $\mathrm{Q}=$ nilai perusahaan ; $\mathrm{D}=$ nilai buku dari total hutang ; EMV = nilai pasar dari ekuitas ; dan $\mathrm{EBV}=$ nilai buku dari ekuitas. EMV (equity market value) diperoleh dari hasil perkalian harga saham penutupan dengan jumlah saham yang beredar. EBV (equity book value) diperoleh dari selisih total aset dengan total kewajiban.

Variabel kedua adalah profitabilitas (X1) yang diukur dengan indikator return on equity (ROE). Formula untuk menghitungnya adalah :

$$
R O E=\frac{\text { Laba Bersih }}{\text { Total Ekuitas }}
$$

Variabel ketiga adalah struktur modal. Struktur modal diukur dengan debt to equity ratio (DER) adalah perbandingan total hutang yang dimiliki perusahaan dengan total ekuitas perusahaan. Formulanya adalah :

$$
D E R=\frac{\text { Total Hutang }}{\text { Total Ekuitas }}
$$

\section{Data}

Populasi dalam penelitian ini adalah 50 perusahaan property dan real estate yang terdaftar di Bursa Efek Indonesia pada periode 2013 - 2016. Pemilihan sampel dilakukan dengan menggunakan teknik purposive sampling dan menghasilkan sampel 26 perusahaan.

\section{Validasi Model}

Model evaluasi PLS berdasarkan pada pengukuran prediksi yang mempunyai sifat non-parametrik.
Oleh karena itu, model evaluasi PLS dilakukan dengan menilai outer model dan inner model (Abdillah \& Jogiyanto, 2015).

Outer model merupakan model pengukuran untuk menilai validitas dan reliabilitas model. Melalui proses iterasi algoritma, parameter model pengukuran (validitas konvergen, validitas diskriminan, composite reability, dan cronbach's alpha) diperoleh, termasuk nilai $\mathrm{R}^{2}$ sebagai parameter ketepatan model prediksi.

Inner model merupakan model struktural untuk memprediksi hubungan kausalitas antar variabel laten. Selanjutnya, evaluasi model dilakukan model dilakukan dengan melihat nilai signifikansi untuk mengetahui pengaruh antar variabel melalui prosedur bootstrapping atau Jeckknifing. Pendekatan bootstrap merepresentasi non parametric untuk precision dari estimasi PLS. Prosedur bootstrap menggunakan seluruh sampel asli untuk melakukan resampling.

\section{Hasil dan Analisis}

Outer Model atau Measurement Model adalah penilaian terhadap reliabilitas dan validitas variabel penelitian. Ada tiga kriteria untuk menilai outer model yaitu: Cross loading, discriminant validity dan composite reliability. Hasil dari outer Model menunjukkan hasil pengujian reliabilitas dan validitas untuk masing-masing variabel. Pada penelitian ini menggunakan indikator formatif. Konstruk dengan indikator formatif tidak dapat dianalisis dengan melihat convergent validity dan composite reability. Oleh karena konstruk formatif pada dasarnya merupakan hubungan regresi dari indikator ke konstruk maka cara menilainya adalah dengan melihat nilai koefisien regresi dan signifikansi dari koefisien regresi tersebut.

Tabel 1. Path Coefficient

\begin{tabular}{lcc}
\hline & $\begin{array}{c}\text { Nilai } \\
\text { Perusahaan }\end{array}$ & $\begin{array}{c}\text { Struktur } \\
\text { Modal }\end{array}$ \\
\hline Profitabilitas & 0,132 & 0,242 \\
Struktur Modal & 0,598 &
\end{tabular}

Sumber : Output software SmartPLS 3.0

Dari tabel 1 diatas, nilai koefisien pengaruh dari profitabilitas terhadap struktur modal sebesar 0,242. Untuk koefisien pengaruh dari profitabilitas terhadap nilai perusahaan adalah sebesar 0,132 dan pengaruh struktur modal terhadap nilai perusahaan sebesar 0,598 .

Pengujian inner model atau model struktural dilakukan untuk melihat hubungan antara variabel, nilai signifikansi dan $R$-square dari model 
penelitian. Setelah mengetahui hubungan yang signifikan antara variabel. dengan demikian, dapat disimpulkan hipotesis untuk masalah penelitian terkait pengaruh langsung dari profitabilitas terhadap struktur modal serta pengaruh langsung dari profitabilitas dan struktur modal terhadap nilai perusahaan. Penelitian ini juga ingin melihat pengaruh tidak langsung dari variabel profitabiltas terhadap nilai perusahaan melalui variabel struktur modal. Pengujian hipotesis dilakukan dengan metode resampling bootstrap. Statistik uji yang digunakan adalah uji statistik uji t.

Tabel 2. R Square

\begin{tabular}{ll}
\hline & R Square \\
\hline Nilai Perusahaan & 0,412 \\
Struktur Modal & 0,058 \\
\hline
\end{tabular}

Sumber : Output software SmartPLS 3.0

Tabel 2 diatas menjelaskan bahwa nilai $R$-square sebesar 0,058 berarti model regresi memiliki tingkat goodness of fit yang lemah, artinya variabilitas struktur modal yang dapat dijelaskan oleh variabel profitabilitas sebesar $5,8 \%$ sedangkan 94,2\% dijelaskan oleh variabel lain diluar model atau penelitian ini. Sementara nilai $R$-square sebesar 0,412 atau $41,2 \%$ nilai perusahaan dipengaruhi oleh struktur modal dan profitabilitas sedangkan 58,8\% yang mempengaruhi nilai perusahaan berasal dari variabel lain diluar penelitian.

\section{Pengaruh Langsung}

Pengaruh langsung adalah hubungan yang signifikan antar varaiabel yang diteliti. Untuk mengetahui signifikan tidaknya hubungan variabel penelitian yang dibangun dapat diliat pada tabel 3 .

Tabel 3. Path Coefficient (Mean,,T-Values,PValues)

\begin{tabular}{llll}
\hline & $\begin{array}{c}\text { Original } \\
\text { Sample }\end{array}$ & T-Value & P-Value \\
\hline $\begin{array}{l}\text { Profitabilitas ----> } \\
\text { Nilai Perusahaan }\end{array}$ & 0,132 & 1,601 & 0,110 \\
& & & \\
$\begin{array}{l}\text { Profitabilitas ----> } \\
\text { Struktur Modal }\end{array}$ & 0,242 & 3,062 & 0,002 \\
$\begin{array}{l}\text { Struktur Modal ---- } \\
>\text { Nilai Perusahaan }\end{array}$ & 0,598 & 9,400 & 0,000 \\
& & & \\
\hline
\end{tabular}

Sumber : Output software SmartPLS 3.0

Berdasarkan tabel 3 dapat disimpulkan bahwa profitabilitas memiliki pengaruh langsung positif dan signifikan terhadap struktur modal (t-hitung $=3,062$ dan $p=0,002$ ). Perusahaan dengan profit yang tinggi cenderung akan menggunakan lebih banyak pinjaman untuk mendapatkan manfaat penggunaan hutang dari aspek pajak.

Struktur modal juga memiliki pengaruh langsung positif dan signifikan terhadap nilai perusahaan (thitung $=9,400$ dan $p=0,000$ ). Hasil ini sesuai dengan trade-off theory, penggunaan hutang dibawah titik optimal akan meningkatkan nilai perusahaan karena bunga hutang dapat menjadi pengurang pajak.

Profitabilitas tidak berpengaruh langsung terhadap nilai perusahaan atau tidak signifikan (t-hitung $=1,601$ dan $p=0,110$ ). Artinya profitabilitas yang tinggi tidak mampu untuk meningkatkan nilai perusahaan. hal ini bisa jadi dikarenakan para investor lebih berorientasi teknikal daripada berorientasi mikro fundamental. Dimana para investor memperkirakan harga saham dengan mengamati perubahan harganya di waktu yang lalu. Perubahan harga saham cenderung bergerak pada satu arah tertentu (trend). Pola tertentu pada masa yang lampau akan terulang kembali pada masa yang akan datang. Hipotesis ketiga ditolak.

\section{Pengaruh Tidak Langsung}

Mengacu pada model penelitian yang dibuat, terdapat 2 (dua) variabel yang berpengaruh secara langsung terhadap nilai perusahaan yaitu profitabilitas dan struktur modal. Hasil pengujian menunjukan bahwa profitabilitas tidak berpengaruh secara langsung terhadap nilai perusahaan. Sedangkan struktur modal berpengaruh secara langsung terhadap nilai perusahaan. Sebagaimana disebutkan sebelumnya, struktur modal dipengaruhi oleh profitabilitas. Jika profitabilitas berpengaruh signifikan terhadap struktur modal, maka tinggal siginifikansi dari struktur modal terhadap nilai perusahaan yang akan menentukan apakah struktur modal dapat berfungsi sebagai intervening variable dalam menjembatani pengaruh tidak langsung profabilitas terhadap nilai perusahaan.

Ulasan sebelumnya telah memastikan bahwa struktur modal secara signifikan berpengaruh terhadap nilai perusahaan, maka tinggal menelusuri apakah profitabilitas signifikan mempengaruhi struktur modal atau tidak. Hasil estimasi model menunjukkan profitabilitas berpengaruh positif dan signifikan terhadap struktur modal. Ini memberikan makna bahwa struktur modal merupakan variabel intervening untuk profitabilitas.

Struktur modal menjadi pure intervening bagi profitabilitas terhadap nilai perusahaan. Dikatakan pure intervening karena secara langsung profitabilitas tidak berpengaruh terhadap nilai perusahaan, profitabilitas akan berpengaruh terhadap nilai perusahaan melalui struktur modal. 


\section{Pengaruh Total}

Q-Square predictive relevance untuk model penelitian ini dapat dihitung dengan rumus sebagai berikut :

$$
\begin{aligned}
\mathrm{Q}^{2} & =1-\left(1-\mathrm{R}_{1}^{2}\right)\left(1-\mathrm{R}_{2}^{2}\right) \\
& =1-(1-0.058)(1-0.412) \\
& =1-(0.942)(0.588) \\
& =1-0.553237 \\
& =0.4467(44.67 \%)
\end{aligned}
$$

Dari hasil perhitugan Q Square diatas dapat diartikan bahwa koefisien determinasi dari model sebesar $44.67 \%$. Berarti variabilitas nilai perusahaan yang dapat dijelaskan oleh dua variabel dalam model sebesar $\quad 44,67 \%$ sedangkan $55.33 \%$ dijelaskan oleh variabel lain yang tidak diteliti dalam model ini.

\section{Kesimpulan}

Pendekatan dengan pengaplikasian Partial Least Square (PLS) pada 26 perusahaan yang terdaftar di Bursa Efek Indonesia (BEI) selang periode 20132016, paper ini memberikan beberapa temuan empiris. Pertama, variabel struktur modal berpengaruh positif dan signifikan terhadap nilai perusahaan. Ini berarti, semakin besar proporsi hutang dalam struktur pendanaan perusahaan, maka semakin besar pula nilai perusahaan tersebut. Kedua, variabel profitabilitas tidak berpengaruh signifikan terhadap nilai perusahaan. Hal ini bisa jadi karena investor lebih tertarik untuk melakukan analisis teknikal daripada fundamental. Ketiga, variabel struktur modal merupakan variabel intervening bagi profitabilitas.

Penelitian ini memiliki beberapa keterbatasan, pertama perusahaan yang menjadi sampel dalam penelitian ini hanya perusahaan yang masuk dalam sektor property dan real estate. Oleh karena itu, agar penelitian mendatang memberikan kekuatan generalisasi yang lebih luas dan lebih baik, diharapkan dapat melibatkan seluruh sektor industri. Kedua, model dalam penelitian ini hanya menggunakan variabel profitabilitas, struktur modal dan nilai perusahaan. dengan demikian; diharapkan penelitian kedepan dapat menginternalisasi variabel-variabel lain yang relevan dalam menentukan nilai perusahaan.

\section{Daftar Pustaka}

Abdillah, W. \& Jogiyanto, 2015. Partial Least Square (PLS) Alternatif Structural Equation Modeling (SEM) dalam Penelitian Bisnis. Yogyakarta: Penerbit ANDI.

Ayem, S. \& Nugroho, R., 2016. Pengaruh Profitabilitas, Struktur Modal, Kebijakan
Deviden dan Keputusan Investasi Terhadap Nilai Perusahaan. Jurnal Akuntansi, Volume 4, pp. 31-39.

Brealey, R. A., Myers, S. C. \& Marcus, A. J., 2012. Dasar-dasar Manajemen Keuangan Perusahaan Jilid 2. Jakarta: Erlangga.

Brigham, E. F. \& Houston, J. F., 2013. Dasar-dasar Manajemen Keuangan, Buku 1 Edisi 11. Jakarta: Salemba Empat.

Fama, E. F., 1978. The Effect of a firms Investment And Financing Decision on the Welfare Of Its Security Holders. American Economic Review, Volume 68, pp. 272-28.

Ghozali, I., 2014. Structural Equation Modeling Metode Alternatif dengan Partial Least Squares (PLS). Semarang: Badan Penerbit UNDIP.

Horne, J. C. V. \& Machowicz, J. M., 2010. Prinsipprinsip Manajemen Keuangan. Jakarta: Salemba Empat.

Husnan, S., 2001. Manajemen Keuangan Teori dan Penerapan (Keputusan Jangka Pendek) Buku 2 Edisi 4. Yogyakarta: BPFE.

Jensen, M. C. \& Meckling, W. H., 1976. Theory of Firm ; Managerial Behavior, Agency Cost and Ownership Structure. Journal of Financial Economics 3, pp. 305-360.

Moniaga, F., 2013. Struktur Modal, Profitabilitas dan Struktur Biaya terhadap Nilai Perusahaan Industri Keramik, Porcelen dan Kaca Periode 2007-2011. Jurnal EMBA, Volume 1, pp. 433442.

Myers, S. C. \& Majluf, N. S., 1984. Corporate Financing and Invesment Decisions When Firms Have Information That Investors Do Not Have. Journal of Financial Economics 13, pp. 187-221.

Nguyen, T. D. K. \& Ramachandran, N., 2006. Capital Structure in Small and Medium Sized Enterprises. ASEAN Economics Bulletin, Volume 23, pp. 192-211.

Prasetia, T. E., Tommy, P. \& Saerang, I. S., 2014. Struktur Modal, Ukuran Perusahaan, dan Risiko Perusahaan terhadap Nilai Perusahaan Otomotif yang terdaftar di BEI. Jurnal EMBA, pp. 879-889.

Prasetyorini, B. F., 2013. Pengaruh Ukuran Perusahaan, Leverage, Price Earning Ratio dan Profitabilitas Terhadap Nilai Perusahaan. Jurnal Ilmu Manajemen, Volume 1, pp. 183196.

Setyawan, A. I. W., Topowijono \& Nuzula, N. F., 2016. Pengaruh Firm Size, Growth 


\section{Jurnal Ekonomi dan Bisnis Indonesia}

Opportunity, Profitability, Business Risk, Effective Tax Rate, Asset Tangibility, Firm Age dan Liquidity Terhadap Struktur Modal Perusahaan. Jurnal Administrasi Bisnis, Volume 31, pp. 108-117.

Tanujaya, D., Rakhman, A. \& Mutiarawati, E. V., 2016. Analisis Pengaruh Profitabilitas dan Struktur Modal Terhadap Nilai Perusahaan
Perbankan yang terdaftar di BEI pada Tahun 2011-2014. Manajemen Keuangan, pp. 129138.

Williams, J., 1988. Efficient Signaling with Dividends, Invesment, And Stock Repurchases. The Journal of Finance, Volume Vol. XLIII, pp. pp. 737-746. 